\title{
Precision Processing AND MICROTOPOGRAPHICAL CHARACTERISATION OF TOOLING INSERTS FOR INJECTION MOULDS
}

\author{
Bliedtner, J.; BUerger, W.; Rosenkranz, S.; \\ MUELLER, W. \& FROEHLICH, M.
}

Abstract: Ranges of plastic parts with optical surfaces can increasingly be manufactured in accordance with the users' demands at a high quality level, due to the technical development towards high-precision manufacturing in the field of injection moulding. Optical surfaces of plastic parts have to be of high quality for functional reasons. In the present case, the user of such components demands that the optically effective flat surfaces have a square value of the average surface roughness $R_{q}$ of $\leq 10 \mathrm{~nm}$.

Key words: model based systems, schedulling and planning, predicate transition petri nets , simulation, specification, verification
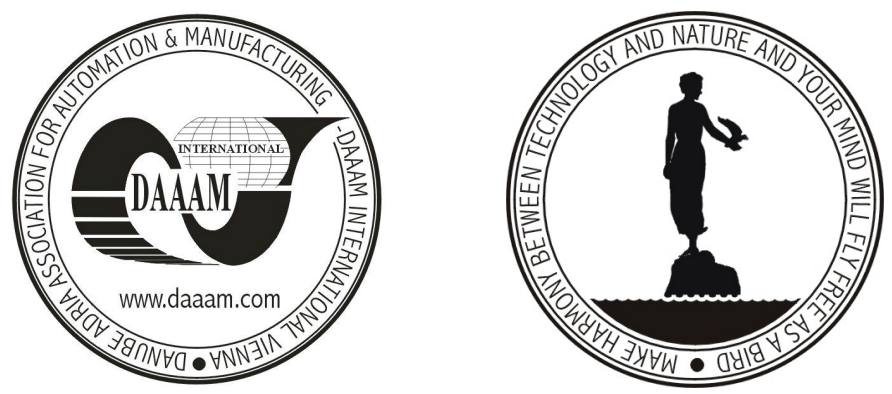

Authors' data: Prof. Bliedtner, J.[ens], Buerger, W.[olfgang], Rosenkranz, S.[andy], Mueller W., Froehlich, M[aik], University of Applied Sciences Jena, Department SciTec, Carl-Zeiss-Promenade 2, D-07745, Jena, Germany, Fresnel Optics GmbH, Flurstedter Marktweg 13, D-099510 Apolda, Germany, JENOPTIK Polymer Systems GmbH, Am Sandberg 2, D-07819 Triptis, Germany, Jens.Bliedtner@fh-jena.de,Wolfgang.Buerger@fh-jena.de, sandy.rosenkranz@fresnel-optics.de,maik.froehlich@jenoptik-ps.de

This Publication has to be referred as: Bliedtner, J.; Buerger, W.; Rosenkranz, S.; Mueller, W. \& Froehlich, M. (2006). Precision Processing and Microtopographical Characterisation of Tooling Inserts for Injection Moulds, Chapter 05 in DAAAM International Scientific Book 2006, B. Katalinic (Ed.), Published by DAAAM International, ISBN 3-901509-47-X, ISSN 1726-9687, Vienna, Austria DOI: $10.2507 /$ daaam.scibook.2006.05 